\title{
The role of traffic's television teasers on reducing driving accidents
}

Hassanzadeh, Mina $\bowtie$

Islamic Azad University, South branch, Tehran, Iran (mhassanzadehr@yahoo.com)

Mahajer, Yahya

Allameh Tabatabaei University, Tehran, Iran (yahyamahajer@yahoo.com)

Sharifan, Ahmad

College of Statistics and Bioinformatics Institute of Sanjesh Organization, Iran (a_sharifan2003@yahoo.com)

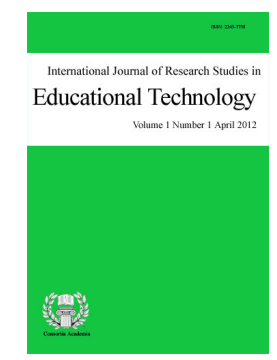

ISSN: 2243-7738 Online ISSN: 2243-7746

OPEN ACCESS

\section{Abstract}

A descriptive survey method was used to determine the relationship between traffic's television teasers and reducing driving accidents. For this purpose, from target statistical population (traffic officers and citizens of district 2 of Tehran), 70 traffic officers and 140 citizens that were resident in three different zones (high-, middle- and low income housing zones) were selected by cluster random sampling as research sample. Data needed for study was collected by using questionnaires that had content validity and internal consistency. To analyze data Chi-squared and Colmogroph-Smirnoph tests were applied. The results were shown that traffic's teasers have had moderate effect on driving accidents and relatively have been effective in promoting the manner of drivers' driving.

Keywords: traffic's television teasers; accidents; traffic officers; citizens; Tehran 


\section{The role of traffic's television teasers on reducing driving accidents}

\section{Introduction}

Current educational programs have always focused in knowledge building (Hsiu-Fen, 2012). In recent half a century, developing machinery life and increasing traffic in roads, versus economic and conventional benefits from expanding communication and transporting good and passenger have given rise to the dramatic increase of road's accidents. Life and financial losses from these traffic's accidents have heavily impacted human society. In coming 20 years, amount of death from traffic's accident, in low and middle income countries increases nearly $80 \%$ whereas, in high income countries, this amount will be reduced to $30 \%$ (Montazeri, 2004). Increasing trend of life losses amount and injuries from accidents in third-world and developing countries like Iran in recent years is alarming. Seventy percent share of human factor that is the most efficient factor in happening road's accidents is indicator of low level of traffic culture. There is a hope with unify and focused management. With forming the immune committee of roads as well as developing transporting services, immune coefficient of roads, focusing on television broadcasters should be promoted and morality from driving accident's should be reduced (Sotoudeh, 2002; Doyle, 2010).

Today, the reality of macro cities indicates that, more increase the number of automobiles, more increase mass and heaviness of traffic giving rise to reducing the speed of movement and long blockades and time losses. Subsequent fatigue and mental disturbance from these induced problems result in the increase of accidents. Minimum level of traffic culture and false manner of driving, have led to indiscipline vehicle transportation coupling with walking passengers creates bad conditions for driving accidents to take place (GharibiHashtjin, 2000). Most studies in this field show that, main cause of the most sudden accident and disasters have been human's unawareness and ignorance in different fields.

In Iran, the accidents in addition to death factor, (550,000 lost life in every year), injuries have allocated highest load resulted from diseases itself (Soori et al., 2008). In fact, road accidents and casualties is an important problem in the country and prompt decision for preventing to emerge of such accidents/costs raises is a priority at the national level. Designing and performing effective programs for road and street immunization, increasing immune coefficient in process of automobile production, law legislation for punishment of offenders and finally designing and performing programs of revising drivers behaviors, passengers of automobiles, drivers of motorcycles, bicyclist and walking passers aiming at decreasing dangerous driving behaviors are of intervention practices that could be considered (Mock, 2004).

On the other hand, experts believe that using heavy penalties and cancellation of offender drivers' licenses is not a main solution to behave to outlaws and do not have significant effects on revising the driving method of drivers. Obviously, using public media can effect somehow on daily life and people's improvement. Also, advertisement and television teasers can have tremendous effect on people and increasing their knowledge about road's immunity. Because, in this field advertisements are very economic, and user's immune state can be changed via media (Asian Development Bank, 1996). All kind of media, especially public media are going to inform society by training about risk of behaviors against health and how to avoid it and reducing its disturbance effect (Lund et al., 2004; Freimuth \& Quinn, 2004).

Baldvin (2001) believes that, it is multimedia teasers that have been produced and displayed in the form of cultural advertisement animation in the way of changing television viewers' insight in order to increasing knowledge and avoiding driving dangerous accidents. Important reasons for road casualties are non-compliance rules and regulations and immune points by drivers because of cultural cases and their lack of awareness and training about rules. Therefore, informing and training by using public media can enable people to access more percent of training programs by low expenses and also can be effective in area of prevention from driving 
accidents (Nadimi \& Borouj, 1993; Elder et al., 2004). According to Sarokhani (1993), the mass media are one the most important factors in changing values, believes and national measures, and are able to form the thoughts of a society with accurate and controlled planning, and direct their behavior in the form of desired toward special direction. Media via presenting social special norms positively, inculcate people that presented behavior in media is suitable social behavior. Therefore, media with showing suitable social behavior provide social conformity based on presented behavior via media (Ezazi, 1994).

Today, there is a trust to national television rather than other media. This medium maintains the highest public communications with broadcasting news, believes, dramas and so on, and functionality delivers the intended message to its audience (Abareshi, 2006). Important properties of television is transporting massage via eye and ear, and also make easier the receiving of massage comparison to other visual and audio media. Unlike newspapers, that reader should have at least literacy, or in the most cases should have high literacy and culture; television is the best media for illiterate or low literate people. Even children can use television programs (JabariNikou, 2000). The aim of this study was to evaluate the effectiveness of television traffic teasers on drivers. The data were collected from the both Tehran's traffic officers and the citizens of Tehran District 2in order to determine the correlation between traffic teasers' broadcast and reducing accidents as a specific aim of this research.

\subsection{Significance of the study}

In a sufficient transportation system, traffic safety is an important parameter and it is influenced by many factors (Mirmohammadi et al., 2013). There are many policies in countries with different financial source and road infrastructure but in a country like Iran, until now safety performances are mainly concentrated on road engineering activities, without much attention for vehicle technology or driving behavior and precautionary planes. This study was designed to evaluate traffic's television teasers that influence drivers' attitude and performance in driving skill acquisition. It therefore presents a prototype for controlling poor performance in driving patterns and highlights the factors that propagate drivers' positive attitude towards safe driving (Azado, 2014). Moreover the findings in this study will add to the knowledge base of effects of attitude towards accident reduction which will be useful in different programs especially in driving behavior and precautionary planes.

\section{Method}

\subsection{Research questions}

Are there any possible differences in the performance of driving patterns of watching traffic teasers and non-watching traffic teaser groups? Is there any possibility to reduce driving accidents by watching traffic training teasers?

\subsection{Participants}

The participants were the trafic officers and citizens of Tehran district 2 who used transportation viecles during a day in the city. Seventhy traffic officers and 140 citizens were selected by clustered-random sampling. Initially, three zones from tehran district 2 including the sectors Saadat abad,Frahzad, Shahrak Gharb, Marzdaran, Pounak, Pol Gisha, Satarkhan, Tarasht were selected randomly. According to the social conditions of the head of family, the participants were then divided into three groups; high, midle and low classes and then they were requested to complete the questionaries.

\subsection{The questionnaires}

This is a questionnaire has 20 questions with multiple choice responses. Its content is based on a study of the library associated with the current sources used in conjunction with a variable effect of driving teasers driving 
Hassanzadeh, M., Mahajer, Y., \& Sharifan, A.

tips and disaster reduction. The required consistency was maintained for questionnaire layout.

\subsection{Data analysis}

In order to calculate the total number of questions with answers against each response and to locate the statistically significant differences between and among the groups, maximum non-parametric tests of Chi-squared and Kolmogorov-Smirnov were conducted. The latter was used to measure the association between the variables.

\subsection{Validation and reliability of instrument}

The questionnaire used in this study was scrutinized by different professionals in statistics. The questionnaire was repeatedly edited and modified following the suggestions stated by these professionals before the final copy was ready. In addition the questionnaire was pre-tested before the actual data collection. In other not to demotivate the respondents and still achieve the reliability the items on the questionnaire was limited to 20 items. This falls within the accepted questionnaire item range recommended by Nunnally (Al-sa'd, 2007) for reliability of a study. The participants were also observed and monitored as they perform each operation unaided.

\section{Results}

The results obtained from analyses of 9 indices were presented in tables 1-9. Police officers and citizens' comments for each survey questions were evaluated with above-mentioned statistical methods. In brief, $93.7 \%$ of ordinary people and $95.7 \%$ of the police officers stated that they significantly have seen traffic teasers (Table 1). Both groups of the participants stated traffic teasers displayed in TV have been moderate impact on its audience (Table 2). Regarding ordinary people and police officers comments about the effectiveness of watching traffic teasers on driving manner and compliance of rules and regulations, $77.7 \%$ of ordinary people and $62.9 \%$ of the police stated the significant impact of teasers at level of 0.05 and 0.001 , respectively (Table 3 ).

\section{Table 1}

Chi-square test for comparing the ordinary people \& traffic police officers opinions about seeing traffic teasers

\begin{tabular}{llll}
\hline Index & Frequency & Degrees of freedom & Calculated Chi-square value \\
\hline $\begin{array}{l}\text { Police officers opinions (N=69): } \\
\text { No }\end{array}$ & $3(\% 4.3)$ & 1 & $57.522^{*}$ \\
Yes & $66(\% 95.7)$ & & \\
Total & $69(\% 100)$ & & $104.348^{*}$ \\
Citizens comments(N=138): & & \\
No & $9(\% 6.5)$ & 1 & \\
Yes & $129(\% 93.5)$ & & \\
Total & $138(\% 100)$ & & \\
\hline
\end{tabular}

Note. ${ }^{*} p<0.001$

Comparing police officers and ordinary people about the influence of the traffic teasers in mind, $65.7 \%$ of police officers and $59 \%$ of ordinary people believed that some driving television broadcast teasers has been influential (Table 4). Results indicated that $53.2 \%$ of individuals and $56.7 \%$ of police officers commented that teaser display has no change in the amount of his driving violations before and after the broadcast (Table 5). As it can be seen in Table 6, the majority of police officers $(55.7 \%)$ and ordinary people $(49.6 \%)$ stated that sometimes they act in response to traffic messages $(p<0.001)$.The data from index 7 indicated, a significant influence $(p<0.001)$ of teasers and police alarming for both groups(Table 7). As shown in table 8 , majority of police officers $(52.9 \%)$ and of ordinary people $(45.3 \%)$ have stated that they have seen sometimes the TV 
The role of traffic's television teasers on reducing driving accidents

broadcaste training teasers. It can be shown in the table 9, the majority of policemen (37.7\%) and ordinary people $(41.4 \%)$ tried to obey the speed limit after watching traffic teasers. Like the other indices, we also noticed significant effects of traffic teasers in encouraging the people to drive within the speed limit.

Table 2

Kolmogorov-Smirnov test for an index comparing the opinion of ordinary people \& traffic on the effectiveness of traffic teasers

\begin{tabular}{llll}
\hline Police officers opinions $(\mathrm{N}=70)$ & Frequency & Percentage frequency & Calculated Z value \\
\hline Very low & 3 & 4.3 & \\
Low & 9 & 12.9 & $1.744^{*}$ \\
Middle & 28 & 40 & \\
High & 25 & 35.7 & \\
Very high & 5 & 7.1 & \\
Total & 70 & 100 & Calculated Z value \\
\hline Citizens opinions $(\mathrm{N}=140)$ & Frequency & Percentage frequency & \\
\hline Very low & 1.4 & 2 & \\
Low & 16 & 11.4 & $2.511^{* *}$ \\
Middle & 54 & 38.6 & \\
High & 50 & 35.7 & \\
Very high & 18 & 12.9 & \\
Total & 140 & 100 & \\
\hline
\end{tabular}

Note. ${ }^{*} p<0.01,{ }^{* *} p<0.001$

Table 3

Result of Chi-square test comparing the opinion of police officers \& ordinary people about effectiveness of watching traffic teasers on manner of driving \& compliance of rules and regulations

\begin{tabular}{llll}
\hline Index & Frequency & Degrees of freedom & Calculated Chi-square value \\
\hline $\begin{array}{l}\text { Police officers opinions }(\mathrm{N}=70): \\
\text { No }\end{array}$ & $26(\% 37.1)$ & 1 & $4.629 *$ \\
Yes & $44(\% 62.9)$ & & \\
Total & $70(\% 100)$ & & \\
Citizens opinions $(\mathrm{N}=140):$ & & & $42.655^{* *}$ \\
No & $31(\% 22.3)$ & 1 & \\
Yes & $103(\% 77.7)$ & & \\
Total & $140(\% 100)$ & & \\
\hline
\end{tabular}

Note. $* p<0.05, * * p<0.001$

Table 4

Indicator of Kolmogorov-Smirnov test for comparing the opinion of police officers \& ordinary people about impact of traffic teaser in the minds of audience

\begin{tabular}{llll}
\hline Police officers opinions $(\mathrm{N}=70)$ & Frequency & \% frequency & Z value \\
\hline Enormous influence & 5 & 7.1 & \\
Some influential & 46 & 65.7 & $3.091 *$ \\
Rarely effective & 19 & 27.1 & \\
Total & 70 & 100 & \\
\hline
\end{tabular}


Hassanzadeh, M., Mahajer, Y., \& Sharifan, A.

Table 4 ... continued

\begin{tabular}{llll}
\hline Citizens opinions $(\mathrm{N}=140)$ & Frequency & \% frequency & Z value \\
\hline Enormous influence & 36 & 25.9 & \\
Some influential & 82 & 59.0 & $3.639^{*}$ \\
Rarely effective & 21 & 15.1 & \\
Total & 140 & 100 & \\
\hline
\end{tabular}

Note. ${ }^{*} p<0.001$

Table 5

Comments of police officers \& ordinary people about the amount of committing driving offenses after traffic teasers broadcast

\begin{tabular}{llll}
\hline Index & Frequency & Degrees of freedom & Calculated Chi-square value \\
\hline Police officers opinions $(\mathrm{N}=70):$ & & \\
No & $38(\% 56.7)$ & 1 & $1.209^{*}$ \\
Yes & $29(\% 43.23)$ & \\
Total & $67(\% 100)$ & \\
Citizens opinions $(\mathrm{N}=140):$ & & \\
No & $67(\% 53.2)$ & $0.508^{*}$ \\
Yes & $59(\% 46.8)$ & \\
Total & $140(\% 100)$ & \\
\hline
\end{tabular}

Note. $* p<0.05$

\section{Table 6}

An index verified by Kolmogorov-Smirnov test comparing the response of police officers \& ordinary people to trained traffic massages

\begin{tabular}{llll}
\hline Police officers opinions $(\mathrm{N}=70)$ & Frequency & \% frequency & Z value \\
\hline All messages watched and practiced & 20 & 28.6 & \\
Sometimes the messages were acted & 39 & 55.7 & \\
Messages had no influence on me & 11 & 15.7 & $2.441^{*}$ \\
Total & 70 & 100 & Z value \\
\hline Citizens opinions(N=140) & Frequency & $\%$ frequency & \\
\hline All messages watched and practiced & 54 & 38.8 & \\
Sometimes the messages were acted & 69 & 49.6 & $3.216^{*}$ \\
Messages had no influence on me & 16 & 11.5 & 100 \\
Total & 140 & &
\end{tabular}

Note. ${ }^{*} p<0.001$

\section{Table 7}

Kolmogorov-Smirnov test comparing the performance of police officers \& ordinary people against the instructions \& warnings given by police \& teaser

\begin{tabular}{llll}
\hline Police officers opinions $(\mathrm{N}=70)$ & Frequency & \% frequency & Z value \\
\hline Very low & 4 & 5.8 & \\
Low & 4 & 5.8 & \\
Middle & 23 & 33.3 & $2.064^{*}$ \\
High & 30 & 43.5 & \\
\hline
\end{tabular}


The role of traffic's television teasers on reducing driving accidents

Table 7 ... continued

\begin{tabular}{llll}
\hline Police officers opinions $(\mathrm{N}=70)$ & Frequency & $\%$ frequency & Z value \\
\hline Very high & 8 & 11.6 & \\
Total & 70 & 100 & Z value \\
\hline Citizens opinions $(\mathrm{N}=140)$ & Frequency & $\%$ frequency & \\
\hline Very low & 4 & 2.9 & $2.848^{*}$ \\
Low & 11 & 7.9 & \\
Middle & 51 & 37.4 & \\
High & 59 & 42.1 & \\
Very high & 15 & 10.7 & \\
Total & 140 & 100 & \\
\hline
\end{tabular}

Note. ${ }^{*} p<0.001$

Table 8

Kolmogorov-Smirnov test comparing police officers \& ordinary people responding to the TV broadcasting teasers

\begin{tabular}{llll}
\hline Police officers opinions $(\mathrm{N}=70)$ & Frequency & \% frequency & Z value \\
\hline I watch carefully & 29 & 41.4 & \\
I watch sometimes & 37 & 52.9 & $2.208^{*}$ \\
I change the channel & 2 & 2.9 & \\
I pay no attention & 2 & 2.9 & \\
Total & 70 & 100 & Z value \\
\hline Citizens opinions $(\mathrm{N}=140)$ & Frequency & $\%$ frequency & $3.238^{*}$ \\
\hline I watch carefully & 63 & 45.3 & \\
I watch sometimes & 62 & 44.6 & 7.2 \\
I change the channel & 10 & 2.9 & 100 \\
I pay no attention & 4 & 140 & \\
Total & & & \\
\hline
\end{tabular}

Note. ${ }^{*} p<0.001$

\section{Table 9}

Kolmogorov-Smirnov test comparing the opinion of police officers \& ordinary people about obeying traffic rules after playing teaser

\begin{tabular}{|c|c|c|c|}
\hline Police officers opinions $(\mathrm{N}=70)$ & Frequency & $\%$ frequency & $\mathrm{Z}$ value \\
\hline Driving with permitted speed & 23 & 37.7 & \\
\hline Avoiding eating and drinking while driving & 2 & 3.3 & \\
\hline Observe the safety distance from the vehicle in front & 17 & 27.9 & \\
\hline Not taking precedence in unauthorized places & 19 & 31.1 & \\
\hline Total & 70 & 100 & $4.024 *$ \\
\hline Citizens opinions $(\mathrm{N}=140)$ & Frequency & $\%$ frequency & $Z$ value \\
\hline Driving with permitted speed & 58 & 41.4 & \\
\hline Avoiding eating and drinking while driving & 20 & 14.3 & \\
\hline Observe the safety distance from the vehicle in front & 38 & 27.1 & \\
\hline Not taking precedence in unauthorized places & 24 & 17.1 & \\
\hline Total & 140 & 100 & $3.127 *$ \\
\hline
\end{tabular}

Note. ${ }^{*} p<0.001$ 


\section{Discussion}

In terms of two research questions, "are there any possible differences in the performance of driving patterns of watching traffic teasers and non-watching traffic teaser groups? Or is there any possibility to reduce driving accidents by watching traffic training teasers" the overall test scores for two groups from analysis of 9 indices presented that traffic training teasers have had moderate effect in reducing driving accidents. The findings may be attributed to the fact that traffic training should be implementing from childhood to bring about significant result. This was in agreement with previous studies carried out by some researchers (JabarlooyShabestari (2006), HabibZadeh and Mohammadi (2005), Ekhtiyari and Shams (2009), Yanovitzky and Bennett (1999), Choulyaraki (2008), Bhatoe (2010) and Peck (2011)). According to them, for changing the traffic behavior of people and promoting the culture of traffic from childhood to adultness, it is necessary to develop certain scientific and practical training programs such as traffic animations in order to increase public awareness about the consequences of accidents and the need to follow traffic rules.

The second research question which addressed the traffic teaser watching drivers, holds that traffic training teasers is not very effective in reducing the accidents? The possible explanation for the findings of our second research question may be due to the fact that the changes in response to traffic teasers are not very impressive. Yet it can be said that, using training traffic teasers that possess attractive and rich training content has its own unique effects in reducing driving accidents. No doubt, the influence of culture media such as local TV is much more pronounced. However, despite many reports on positive effects of traffic teasers in reducing the rate of accidents in different countries, its role is still moderate.

\subsection{Practical implications}

The positive influence of traffic television teasers on performance in driving skill acquisition could be traced to the adoption of practical approach in teaching the drivers which allowed the drivers to implement driving skills in the face of challenges and continuous engagement of skills in driving patterns.

\section{Implications for trainers}

Considering the beneficial impacts of driving learners' attention to more visual support, driving trainers are expected to invest more time on using video material (Mehdi \& Mirzaee, 2014). This can be achieved by incorporating the new technological advances for general public and using movies as a part of everyday classes for individuals. However, the kind of task we expect from them must differ according to learners' proficiency level.

\section{Conclusion}

Choosing a region from Tehran city (district 2), using a single analytical method, the low number of target groups as well as the lack of personnel to track the results of this educational approach, are of the limitations of current study. Therefore, it would be suggested further studies to be carried out in different cities and in large scales in order to determine the exact role of traffic teasers in reducing the number of deaths and serious injuries caused by road accidents. Subsequently, it will be possible to generalize findings of this research. Other complementary studies are required to be conducted in order to assess the impact of other public media such as radio, press, internet and audio visual equipment in traffic safety issue. Furthermore, it is recommended to the designers and manufacturers to produce better training programs such as creative videos by editing, combining, and organizing pre-existing material (Mortazavi, 2006; Dusi et al., 2011).

Acknowledgements: The authors are highly appreciated Dr. F. Ghajar efforts in reviewing this revised manuscript. 


\section{References}

Al-sa'd, A. (2007). Evaluation of students' attitudes towards vocational education in Jordan. Malmö Studies in Educational Sciences, 32, 1-185.

Abareshi, A. (2006). Investigating the effect of television training \& advertising teasers in social problems. Unpublished masteral thesis, Islamic Azad University, Tehran Centre Branch, Iran. Asian Development Bank (1996). Road Immune Management. Translated into Persian by M. Ghorbani \& M. Nouri Amir), Tehran: Transportation Researching Publication.

Azodo, A. P. (2014). Attitude influence on performance in technical skill acquisition among formal technical trainees. International Journal of Research Studies in Education, 3(5), 1-10. http://dx.doi.org/10.5861/ijrse.2014.838

Baldvin, H. (2001). How do we make television teaser. Translated into Persian by H. Garshasbi, Tehran: Soroush Publication.

Bhatoe, S. H. (2010). Youthful driving parents and peers. Indian Journal Neurotrauma, 7(1), 1-4. http://dx.doi.org/10.1016/S0973-0508(10)80002-4

Chouliaraki, L. (2008). The media as moral education: Mediation and action. Media, culture and society, 30(6), 831-852. http://dx.doi.org/10.1177/0163443708096096

Doyle, G. (2010). From television to multi-platform: Less from more or more for less? Convergence: The International Journal of Research into New Media Technologies, 16(4), 1-19. http://dx.doi.org/10.1177/1354856510375145

Dusi, N. M., Federico, M., \& Furini, M. (2011). Movieremix: Having fun playing with videos. International Journal of Computer Games Technology, 2011(1), 1-13. http://dx.doi.org/10.1155/2011/857371

Ekhtiyari, E., \& Shams, M. (2009). Media mobilization of training informing and prevention from traffic accidents. Journal of Police Management, 4(2) 267-252.

Elder, R. W., Shults, R. A., Sleet, D. A., Nichols, J. A., Thompson, R. S., \& Rajab, W. (2004). Effectiveness of Mass media campaigns for reducing drinking and driving and alcohol-involved crashes: A Systematic Review. American Journal of Preventive Medicine, 27(1), 57-67. http://dx.doi.org/10.1016/j.amepre.2004.03.002

Ezazi, Sh. (1994). Family and television. Tehran: Marandiz Publication.

GharibiHashtjin, F. (2000). Investigating traffic in the center part of Tehran city and limited area of traffic plan. Unpublished masteral thesis, Islamic Azad University, Tehran Center Branch, Iran.

Freimuth, V. S., \& Quinn, S. C. (2004). The contributions of health communication to eliminating health Disparities. American Journal of Public Health, 94(12), 2053-2055. http://dx.doi.org/10.2105/AJPH.94.12.2053

Habibzadeh, A., \& Mohammadi, A. (2005). Investigation the role of television teasers of police assistance in reducing driving crimes in Tehran city. Journal of Police Knowledge, 7(24), 96-74.

Hoover, S. M. (1988). Mass media religions: The Social Sources of the Electronic Church. Beverly Hills, CA: Sage Publications.

Hsiu-Fen, L. (2012). A review on the pragmatic approaches in educating and learning creativity. International Journal of Research Studies in Educational Technology, 1(1), 13-24. http://dx.doi.org/10.5861/ijrset.2012.v1i1.39

JabariNikou, A. (2000). Reasons of tendency towards television. Unpublished bachelor thesis, Islamic Azad University, Tehran North Branch, Iran.

JabarlooyShabestrai, B. (2006). The role of television general services teasers in prevention and reduction of country's road and driving accidents. Proceedings of 7th conference of Iran's transportation and traffic engineering. Retrieved from http://www.ascilite.org.au/conferences/auckland09/procs/baharun.pdf

Lund, J., \& Aaro, L. E. (2004).Accident prevention: presentation of a model placing emphasis on human, structural and cultural factors, Safety Science, 42(4), 271-324. http://dx.doi.org/10.1016/S0925-7535(03)00045-6

Mirmohammadi, F., Khorasani, G, Tatari, A., Yadollahi, A., Taherian, H., Motamed, H., Fazelpour, S., 
Hassanzadeh, M., Mahajer, Y., \& Sharifan, A.

Khorasani, M., \& Maleki Verki, M. 2013. Investigation of road accidents and casualties factors with MCDM methods in Iran. Journal of American Science, 9(7s), 11-20.

Mehdi, L., \& Mirzaee, A. (2014). Visual support in assessing listening comprehension: Does it help? International Journal of Research Studies in Educational Technology, 3(2), 1-8. http://dx.doi.org/10.5861/ijrset.2014.814

Mock, C., Quanesh, R., Krishnan, R. Arreola-Risa, C., \& Rivara, F. (2004). Strengthening the prevention and care of injuries worldwide. The Lancet, 363 (26), 2172-2179. http://dx.doi.org/10.1016/S0140-6736(04)16510-0

Montazeri, A. (2004). Road-traffic-related mortality in Iran: A descriptive study. Public Health, 118 (2), 110-113. http://dx.doi.org/10.1016/S0033-3506(03)00173-2

Mortazavi, M.R. (2006). The effect of public media in changing insight and culture. Proceedings of $7^{\text {th }}$ conference of Iran's transportation \& traffic engineering. Retrieved 11 August, 2012 from http://www.civilica.com/Paper-TTC07-TTC07_090.html

Nadimi, M., \& Borouj, M. (1993). Primary, guidance, high education ( $2^{\text {nd }}$ ed.). Tehran: Mehdad Publication.

Peck, R. C. (2011). Do driver training programs reduce crashes and traffic violations? A critical examination of the literature. IATSS Research, 34, 63-71. http://dx.doi.org/10.1016/j.iatssr.2011.01.001

Sarokhani, B. (1993). Communication Sociology (2 $2^{\text {nd }}$ ed.). Tehran: Etelaat Publication.

Soori, H., Eini, A. Mahfouz Pour, S, MasoudiNezhad, M. HatamAbadi, H, Vafayee, R., \& RezazadehAzari, M. (2008). The role of behavioral factors in pathology of traffic accidents. Journal of Rahvar Police, 5(2), 124-134.

Sotoudeh, M. H. (2002). Investigating the immune problems of country's roads focusing on organizing entrance of cities. Unpublished masteral thesis, Islamic Azad University, Tehran Centre Branch, Iran.

Yanovitzky, I., \& Bennett, C. (1999). Media attention, institutional response, and health behavior change: The case of drunk driving, 1978-1996. Communication Research, 26(4), 429-453. http://dx.doi.org/10.1177/009365099026004004 